\title{
Breast Tumor Angiogenesis and Tumor-Associated Macrophages: Histopathologist's Perspective
}

\author{
Ewe Seng Ch'ng, Hasnan Jaafar, and Sharifah Emilia Tuan Sharif \\ Department of Pathology, School of Medical Sciences, Universiti Sains Malaysia, 16150 Kubang Kerian, Kelantan, Malaysia \\ Correspondence should be addressed to Ewe Seng Ch’ng, chngeweseng@hotmail.com
}

Received 15 September 2010; Revised 15 November 2010; Accepted 21 January 2011

Academic Editor: Beiyun Chen

Copyright () 2011 Ewe Seng Ch'ng et al. This is an open access article distributed under the Creative Commons Attribution License, which permits unrestricted use, distribution, and reproduction in any medium, provided the original work is properly cited.

\begin{abstract}
Much progress has been made since the conceptualization of tumor angiogenesis - the induction of growth of new blood vessels by tumor-as a salient feature of clinically significant primary or metastatic cancers. From a practicing histopathologist's point of view, we appraise the application of this concept in breast cancer with particular reference to the evaluation of proangiogenic factors and the assessment of new microvessels in histopathological examination. Recently, much focus has also been centered on the active roles played by tumor-associated macrophages in relation to tumor angiogenesis. We review the literature; many data supporting this facet of tumor angiogenesis were derived from the breast cancer models. We scrutinize the large body of clinical evidence exploring the link between the tumor-associated macrophages and breast tumor angiogenesis and discuss particularly the methodology and limitations of incorporating such an assessment in histopathological examination.
\end{abstract}

\section{Introduction}

Angiogenesis, the growth and remodeling of new blood vessels, is one of the hallmarks of cancer. Acquiring proangiogenic phenotype, tumor cells produce and release proangiogenic factors to initiate angiogenesis whereby the ensuing tumor growth, invasion, and metastasis take place. Subject to this angiogenic switch tenet for its progression, breast cancer has been shown to produce a number of proangiogenic factors. Studies have demonstrated that the evaluation of these proangiogenic factors carries predictive and prognostic values $[1,2]$. Prognostic significance of tumor angiogenesis has also been highlighted in clinical studies where higher microvessel densities correlate with poorer survival outcome [3]. Via the control of angiogenesis, another dimension in therapeutic intervention is now unfolded.

In relation to tumor angiogenesis, recent research also focuses on the role of tumor microenvironment. Tumor-associated macrophages, a major component in the leukocytic infiltration in tumor, have aroused much research interest since the propositions of their active involvement in tumor progression $[4,5]$. Best summarized as M2 phenotype, tumor-associated macrophages show anti-inflammatory and tumor-promoting characteristics, especially in relation to tumor angiogenesis. Apart from the in vitro and in vivo animal studies based on the breast cancer models, there is accumulating evidence from the clinical studies that suggests tumor-promoting features of tumor-associated macrophages in breast cancer $[6,7]$.

In this paper, we outline the conceptual development of breast tumor angiogenesis and evaluate the methodology and limitations of quantifying proangiogenic factors and microvessel density in the assessment of tumor angiogenesis in breast cancer. We summarize the pertinent experimental and clinical data exploring the link between the tumorassociated macrophages and breast tumor angiogenesis, emphasizing the methodology and limitations of histopathological assessment in this regard.

\section{Breast Cancer and Tumor Angiogenesis}

2.1. Tumor Angiogenesis Is One of the Hallmarks of Cancer. Cancer development and progression is a complex multistep process where novel capabilities, the hallmarks of cancer, are acquired through the accumulation of multiple genetic alternations. These hallmarks of cancer include not only the 
tumor's cellular autonomy such as self-sufficiency in growth signals and limitless replicative potential but also the abilities to interact with the surrounding stroma such as development of sustained angiogenesis [8]. In particular, the ability to activate angiogenesis plays a crucial role in controlling tumor progression because tumor growth, invasion, and metastasis are angiogenesis dependent [9].

Folkman first proposed angiogenesis dependency of tumor growth and metastasis in 1971. He hypothesized that tumor would remain in dormancy at a microscopic size (1-2 millimeter) in the absence of angiogenesis [10]. This is comprehensible because a tumor, similar to its nonneoplastic counterpart, requires adequate supply of oxygen and nutrients and an effective means to dispose its waste products for survival and growth; these metabolic needs can be fulfilled through tumor-induced angiogenesis [11]. In fact, all mammalian cells including the tumor cells are restricted to within $100-200 \mu \mathrm{m}$ of a capillary blood vessel due to oxygen diffusion limit of about $100 \mu \mathrm{m}$ [12].

In addition, angiogenesis facilitates metastasis. The newly formed tumor blood vessels are structurally abnormal. For instance, increased numbers of fenestrations, vesicles, and vesicovacuolar channels and a lack of normal basement membrane are common in tumor vessels [13]. These abnormal blood vessels are consequently more permeative and would constitute the easier entry point for tumor cells to enter into the circulation and hence distant micrometastases [14]. The ensuing micrometastases at ectopic places would remain dormant unless secondary angiogenesis occurs and paves the way for the establishment of a clinically evident disease [15].

Angiogenic switch concept has been postulated to explain the mechanism underlying tumor dependence on angiogenesis to escape from dormancy. Under this concept, the balance of proangiogenic and antiangiogenic factors would ultimately determine the activation status of the switch. When the balance is tilted towards the angiogenic end, the angiogenic switch is turned on; transition from the avascular phase into the vascular phase will be triggered, permitting exponential tumor growth and subsequent transformation into an aggressive phenotype [16].

Factors regulating this angiogenic switch have been extensively explored across various tumors. More than 40 endogenous proangiogenic and antiangiogenic factors are now known [17].

\subsection{Immunohistochemical Evaluation of Proangiogenic Factors} Produced by Breast Cancer Needs Validation. Subject to the angiogenic switch tenet for its progression, angiogenesis has been shown by studies to be initiated in the hyperplastic state and to intensify towards the invasive carcinoma end of spectrum in breast cancer [18-20]. Breast cancer has been shown to express at least six different proangiogenic factors. These include vascular endothelial growth factor (VEGF) and its four isoforms (121, 165, 189, and 206 amino acids), transforming growth factor (TGF)- $\beta 1$, pleiotrophin, acidic and basic fibroblast growth factor (FGF), placental growth factor, and thymidine phosphorylase (plateletderived endothelial cell growth factor) [21].
Among these factors, VEGF and associated factors have been the centre of many studies addressing the clinical significance of proangiogenic factors in terms of predictive and prognostic values. In predicting the response to chemotherapy or tamoxifen, higher level of VEGF in tumor by immunohistochemistry or in tumor cytosol by EIA/ELISA method forecasted poorer response in a number of studies [1]. In a review of breast cancer patients, an overwhelming $81 \%$ of 37 clinical studies demonstrated that the VEGF level in tumor or serum, as determined by either immunohistochemistry or ELISA method, serves as an adverse prognostic marker for disease-free or overall survival [2].

Selected studies within the last 10 years exploring the prognostic significance of VEGF and associated factors in breast cancers using immunohistochemistry methodology are highlighted in Table 1, considering immunohistochemistry as a part of routine histopathological examination. As shown in Table 1, many recent studies performing immunohistochemistry in evaluating the expression of VEGF and associated factors failed to demonstrate the prognostic values of these factors in terms of disease-free survival or overall survival [22-37]. Some studies showed that these proangiogenic factors act as a poor prognostic marker but lose their significance in multivariate analysis [38-48]. A number of limitations in the immunohistochemistry methodology could account for these observations. Morphometric assessment is inevitably subject to the individual evaluator's subjectivity. In addition, there is no validated uniform scoring system employed in the reported studies. Primary detecting antibodies from various sources in these studies would give rise to variable detection sensitivity and specificity of the targeted proangiogenic factors. The establishment of a validated immunohistochemistry evaluation is therefore essential to gain comparable data across clinical studies. In addition, this is particularly relevant if the pathology reporting of breast cancer is to incorporate information regarding proangiogenic factors for therapeutic consideration in view of availability of antiangiogenic therapy in on-going clinical trials.

\subsection{Methodological Inconsistency in the Assessment of Tumor} Vascularity in Breast Cancer Limits Its Clinical Prognostic Value. Apart from the evaluation of the regulating factors in the angiogenic switch, the quantification of angiogenesis in breast cancer per se has its own clinical prognostic values. In a landmark paper, Weidner et al. demonstrated that by immunostaining the blood vessels, the number of microvessels per 200x field in the highest neovascularization areas (hot spots) correlated with distant metastasis in breast cancer patients, corresponding to a 1.17-fold (95\% CI = $1.02,1.34)$ increase in the distant metastasis risk for every increase in 10 microvessels [49]. Since then, microvessel density determined by this method and its variants has become the most popular surrogate marker in assessing angiogenesis across various cancers [50]. In breast cancer, higher microvessel densities predict higher risk of subsequent in situ cancers and invasive recurrence of previous in situ cancers [51], poorer response to treatment [52], and higher occurrence of micrometastases [53-55]. In a metaanalysis of 25 independent studies, high microvessel density 
TABLE 1: Summary of the selected studies in the last 10 years exploring the prognostic significance of VEGF and associated factors using immunohistochemistry in breast cancers.

\begin{tabular}{|c|c|c|}
\hline Patients & Assessment of VEGF expression & Prognostic value of VEGF expression \\
\hline $\begin{array}{l}98 \text { stage II ductal breast cancers } \\
{[26]}\end{array}$ & $\begin{array}{l}\text { Antibody: monoclonal anti-VEGF } 165 \\
\text { Scoring system: } 0=\text { none, } 1=<33 \%, 2=33-66 \% \text {, } \\
3=>66 \% \text { positive tumor cells }\end{array}$ & $\begin{array}{l}\text { VEGF had no prognostic significance for overall } \\
\text { survival or disease-free survival }\end{array}$ \\
\hline $\begin{array}{l}48 \text { triple negative breast cancers } \\
\text { not receiving systemic adjuvant } \\
\text { treatment from } 500 \text { primary } \\
\text { breast cancers using tissue } \\
\text { microarrays [24] }\end{array}$ & $\begin{array}{l}\text { Antibody: polyclonal anti-VEGF } \\
\text { Scoring system: cytoplasmic staining intensity was } \\
\text { scored from } 0 \text { to } 3 \\
\text { High expression had score } 3\end{array}$ & $\begin{array}{l}\text { VEGF had no prognostic significance for 5-year } \\
\text { breast-cancer-specific survival }\end{array}$ \\
\hline $\begin{array}{l}125 \text { stage II node-positive } \\
\text { invasive ductal carcinomas, NOS } \\
25 \text { stage II node-positive invasive } \\
\text { lobular carcinomas [23] }\end{array}$ & $\begin{array}{l}\text { Antibody: polyclonal anti-VEGF-C } \\
\text { Staining was graded as strong, medium, or } \\
\text { weak-to-absent expression }\end{array}$ & $\begin{array}{l}\text { VEGF-C had no prognostic significance for } \\
\text { overall survival or disease-free survival }\end{array}$ \\
\hline 172 primary breast cancer [25] & $\begin{array}{l}\text { Antibody: anti-VEGF-A } \\
\text { Scoring system: staining intensity was graded } \\
\text { from } 0 \text { (negative) to } 3 \text { (strong intensity) } \\
\text { Positive cases had score } 1-3\end{array}$ & $\begin{array}{l}\text { VEGF-A had no prognostic significance for } \\
\text { recurrence-free survival }\end{array}$ \\
\hline $\begin{array}{l}116 \text { invasive ductal breast cancers } \\
\text { [27] }\end{array}$ & $\begin{array}{l}\text { Antibody: anti-VEGF } \\
\text { Scoring system: positive cases had }>10 \% \text { positive } \\
\text { tumor cell staining }\end{array}$ & $\begin{array}{l}\text { VEGF-A had no prognostic significance for } \\
\text { overall survival in multivariate analysis }\end{array}$ \\
\hline $\begin{array}{l}52 \text { infiltrating ductal carcinomas, } \\
4 \text { intraductal carcinomas, } 3 \\
\text { mucinous adenocarcinomas, } 1 \\
\text { medullary carcinoma, } 1 \\
\text { inflammatory breast carcinoma } \\
{[38]}\end{array}$ & $\begin{array}{l}\text { Antibody: anti-VEGF-C, anti-VEGF-D } \\
\text { Scoring system: sum of staining intensity ( } 0= \\
\text { negative to } 3=\text { strong) and percentage of positive } \\
\text { cells }(0=0 \%, 1=1-10 \%, 2=11-30 \%, 3= \\
31-50 \%, 4=51-100 \%) \\
\text { High-expression group had score } 4-7\end{array}$ & $\begin{array}{l}\text { High expression of VEGF-C/D had poorer } \\
\text { disease-free survival and overall survival }\end{array}$ \\
\hline $\begin{array}{l}59 \text { invasive ductal carcinomas, } \\
\text { NOS } 11 \text { other types of invasive } \\
\text { breast cancer [39] }\end{array}$ & $\begin{array}{l}\text { Antibody: polyclonal anti-VEGF-C } \\
\text { Scoring system: negative, } 1+(\text { focal expression in } \\
<5 \%), 2+\text { (focal expression in 5-20\%), 3+ } \\
\text { (diffuse expression in }>20 \% \text { ) } \\
\text { High-expression group had score above } 2+\end{array}$ & $\begin{array}{l}\text { Shorter disease-free survival and overall survival } \\
\text { for high expression of VEGF-C in univariate } \\
\text { analysis }\end{array}$ \\
\hline
\end{tabular}

215 high-risk primary breast cancers with extensive axillary involvement [28]
Antibody: monoclonal anti-VEGF

Staining intensity was graded from 0 to $3+$

Positive cases are those having any tumor areas with positive staining
VEGF had no prognostic significance for overall survival or relapse-free survival
Antibody: monoclonal anti-VEGF-A, Scoring system: H score (multiplying percentage of positive carcinoma cells by the staining intensity graded 0 to 3 )

High-expressing tumors had score above the median score anti-VEGF-D, polyclonal anti-VEGF-C

(1) Shorter overall survival for high expression of VEGF-A in univariate analysis

(2) Shorter overall survival and disease-free interval for high expression of VEGF-C in univariate and multivariate analyses

(3) No prognostic significance for VEGF-D

(4) Tumours with high expression of both

VEGF-A and -C had significantly shorter overall survival

Antibody: polyclonal anti-VEGF-B, monoclonal anti-VEGF-A $(165,189,206$ a.a. $)$

130 invasive ductal carcinomas, 30 invasive lobular carcinomas [41]

Scoring system: 0 (no or weak staining in $<10 \%$ ), 1 (weak-to-moderate staining in 11-20\%), 2 (moderate-to-strong staining 21-50\%), 3 (strong staining in $>50 \%$ )

Positive cases had score above 2

136 invasive ductal carcinomas, 31 invasive lobular carcinomas [42]
Antibody: polyclonal anti-VEGF-C, polyclonal anti-VEGF-D

Scoring system: positive cases had at least $10 \%$ immunoreactive tumor cells
Poorer overall survival for VEGF-C-positive cases VEGF-D had no prognostic significance
(1) VEGF-A had no prognostic significance (2) Unfavorable disease-free and overall survival for VEGF-B-positive cases in lymph node metastases cases 
TABle 1: Continued.

\begin{tabular}{l} 
Patients \\
\hline 80 invasive ductal carcinomas, 15 \\
ductal carcinomas in situ, 5 \\
lobular carcinomas in situ, 14 \\
invasive lobular carcinomas, 6 \\
medullary carcinomas, 2 tubular \\
carcinomas [43]
\end{tabular}

114 breast cancers [29]

100 invasive ductal carcinomas, NOS, 19 invasive lobular carcinomas [30]

323 invasive breast carcinomas [31]

181 invasive ductal carcinomas,

22 invasive lobular carcinoma, 8 invasive ductal and lobular (mixed) carcinomas, 5 ductal in situ carcinomas, 1 medullary carcinoma [32]

238 invasive breast cancers not receiving tamoxifen from 500 primary breast cancers using tissue microarrays [22]

tissue microarrays [22]

87 primary breast cancers [33]

224 invasive breast cancers using tissue microarrays [44]

Assessment of VEGF expression

Antibody: monoclonal anti-VEGF

Scoring system: $0=$ none, $1+=<5 \%, 2+=$

$5-50 \%, 3+=>50 \%$ positive tumor cells

High reactivity cases had score above median value

Antibody: monoclonal anti-VEGF165

Scoring system: staining intensity was graded from 0 (no staining) to III (most intense staining)

Antibody: polyclonal anti-VEGF-C

Staining was graded as strong, medium, or weak expression

Antibody: monoclonal anti-VEGF

Scoring system: sum of staining intensity $(0=$ negative to $3=$ strong) and percentage of positive cells $(0=0 \%, 1=1-25 \%, 2=26-50 \%, 3=>50 \%)$

Positive cases had score $4-6$

\section{Antibody: anti-VEGF-C}

Scoring system: cytoplasmic staining was graded negative (negative), $1+(10-39 \%), 2+(40-69 \%)$, $3+(>70 \%)$

Antibody: polyclonal anti-VEGF

Scoring system: cytoplasmic staining intensity was scored from 0 to 3

High staining intensity group had score 3

Antibody: polyclonal anti-VEGF-C

Scoring system: 0 (no staining or cytoplasmic staining in $<10 \%), 1+$ (faint cytoplasmic staining in $>10 \%$ ), $2+$ (weak-to-moderate complete cytoplasmic staining in $>10 \%$ ), $3+$ (strong complete cytoplasmic staining in $>10 \%)$

Positive cases had score $2+$ or $3+$

Antibody: polyclonal anti-VEGF

Scoring system: staining intensity was graded from 0 (negative) to 3 (intense intensity), and the percentage of positive cells was recorded $(0=0 \%$, $1=<1 \%, 2=1-10 \%, 3=10-50 \%, 4=50-90 \%, 5$ $=>90 \%$ )

Positive cases are those having any positive staining

Antibody: polyclonal anti-VEGF-D

Scoring system: $0=$ negative, $1=$ weak focal

207 invasive breast carcinomas [34] staining, 2 strong focal/widespread moderate staining, 3 = strong widespread staining Positive cases had score 2 or 3

96 invasive ductal carcinomas, 9 other invasive carcinomas [45]

Antibody: monoclonal anti-VEGF-D

Scoring system: positive cases had more than $10 \%$ tumor cells with cytoplasmic staining

Antibody: monoclonal anti-VEGF (isoforms 121, 165 and 189)

228 invasive unilateral breast carcinomas [35]

Scoring system: positive cases had more than $1 \%$ immunoreactive tumor cells

114 invasive ductal carcinomas, 9 other invasive carcinomas [46]
Antibody: polyclonal anti-VEGF-C

Scoring system: positive cases had more than $10 \%$ immunoreactive tumor cells
Prognostic value of VEGF expression

Overexpression of VEGF had both unfavorable overall survival and disease-free survival

VEGF had no prognostic significance for disease-free survival or cancer survival

VEGF-C had no prognostic significance for overall survival or disease-free survival

VEGF was not associated with incidence of relapse or death

VEGF-C had no prognostic significance for disease-free survival

VEGF had no prognostic significance for relapse-free survival

VEGF-C had no prognostic significance for disease-free survival or overall survival

VEGF-A-positive cases had favorable disease-free survival at 10 -year followup in multivariate analysis

VEGF-D had no prognostic significance for overall survival or relapse-free survival

(1) Positive VEGF-D cases had poorer disease-free survival in univariate and multivariate analyses

(2) Positive VEGF-D cases had poorer overall survival in univariate analysis

VEGF had no prognostic significance for overall survival or relapse-free survival

Positive VEGF-C cases had poorer disease-free survival and overall survival in univariate analysis 
TABLE 1: Continued.

\begin{tabular}{|c|c|c|}
\hline Patients & Assessment of VEGF expression & Prognostic value of VEGF expression \\
\hline $\begin{array}{l}99 \text { invasive ductal carcinomas, } \\
\text { NOS [36] }\end{array}$ & $\begin{array}{l}\text { Antibody: anti-VEGF } \\
\text { Scoring system: positive cases had more than } 10 \% \\
\text { tumor cells with membrane or cytoplasmic } \\
\text { staining }\end{array}$ & $\begin{array}{l}\text { VEGF had no prognostic significance for overall } \\
\text { survival or relapse-free state }\end{array}$ \\
\hline $\begin{array}{l}107 \text { primary invasive breast } \\
\text { carcinomas [47] }\end{array}$ & $\begin{array}{l}\text { Antibody: anti-VEGF-A, anti-VEGF-C, } \\
\text { anti-VEGF-D } \\
\text { Scoring system: computer-assisted image analysis } \\
\text { based on the percentage of immunostained } \\
\text { surfaces and mean optical density } \\
\text { High-expression group had value equal to or } \\
\text { higher than median }\end{array}$ & $\begin{array}{l}\text { (1) High-VEGF-A-expression cases had worser } \\
\text { disease-free survival } \\
\text { (2) VEGF-C or VEGF-D had no prognostic } \\
\text { significance } \\
\text { (3) Cases with both low VEGF-A and VEGF-C } \\
\text { expression had better disease-free survival }\end{array}$ \\
\hline $\begin{array}{l}242 \text { node-negative breast cancer } \\
\text { [37] }\end{array}$ & $\begin{array}{l}\text { Antibody: polyclonal anti-VEGF isoforms } 121 \text {, } \\
\text { 165, 189, and } 206 \\
\text { Scoring system: high-expression cases had }>40 \% \\
\text { immunopositive tumor cells }\end{array}$ & $\begin{array}{l}\text { VEGF had no prognostic significance for } \\
\text { disease-free survival or overall survival }\end{array}$ \\
\hline $\begin{array}{l}94 \text { invasive breast cancer, } 4 \\
\text { noninvasive cancer }[48]\end{array}$ & $\begin{array}{l}\text { Antibody: polyclonal anti-VEGF-C } \\
\text { Scoring system: positive cases had over } 10 \% \\
\text { tumor cells stained positively }\end{array}$ & $\begin{array}{l}\text { VEGF-C-positive group had poorer disease-free } \\
\text { survival }\end{array}$ \\
\hline
\end{tabular}

significantly predicted poor relapse-free survival and overall survival (both $\mathrm{RR}=1.54,95 \% \mathrm{CI}=1.29,1.84$ ) [3].

However, scrutinizing each of the studies included in the above-mentioned meta-analysis, variations in results regarding prognostic value of microvessel density in breast cancer patients' survival are apparent [3]. The choice of antibodies to highlight the blood vessels in various studies could be a contributing factor because each antibody has its own specificity and sensitivity against the endothelial cells of the blood vessels. Among the commonly used antibodies are antibodies against factor-VIII-related antigen, CD31, and CD34. Anti-CD34 is now considered the optimal marker for its higher sensitivity without high failure rate in antigen retrieval for invasive breast carcinoma studies [3, 56-58].

Another factor to consider in assessing microvessel density is the variations from the original method designed by Weidner et al. These include variables such as the number of hot spots counted, the areas and fields of magnification (magnification of a field area of $200 x$ or $400 x$ ), the subjectivity in identification of what constitutes a stained blood vessel, and also the descriptive statistics in reporting the number of microvessel density (the mean or the highest value). To overcome the subjectivity of observers, a 25-point Chalkley microscope eyepiece graticule has been introduced. The graticule is orientated in such a way that it gives the maximum number of graticule points overlapping the highlighted vessels. This method measures relative area and has strong association with vessel area and number [3, 57-59]. Both the conventional optical assessment method and the Chalkley method have been used in studies that demonstrated increased microvessel density as a poor prognostic factor $[3,60,61]$. Controversies over the best methodology remain despite a proposed consensus of using Chalkley method in angiogenesis quantification in solid human tumors [58].
2.4. Antiangiogenic Therapy Gives Promising Results in Preclinical Studies but Not in Clinical Trials of Metastatic Breast Cancer. Given the pivotal roles of proangiogenic factors in tumor angiogenesis, these factors serve as reasonable pharmacological targets for inhibition of tumor angiogenesis. Among these factors, blockage of the VEGF pathways was the focus of many preclinical studies because VEGF is the most potent proangiogenic factor [62].

A number of experimental xenograft models using different tumor cell types including breast carcinomas showed that anti-VEGF therapy resulted in $25 \%$ to $95 \%$ of tumor growth inhibition in a dose-dependant manner. Functionally, tumor microvascular permeability was also reduced [63]. Upon antiangiogenic drug treatment, tumor vessels remodel and transiently resemble the normal vessels. During this normalization window, the normalized tumor vessels are believed to be more efficient in delivering the nutrients as well as cytotoxic drugs and oxygen, potentiating the effects of the combination of cytotoxic and antiangiogenic therapies targeting the tumor cells and endothelial cells, respectively [64, 65]. This tumor vasculature normalization model provides a rationale for the observed better effects of combined cytotoxic and anti-VEGF therapy as compared to single-agent treatment in preclinical studies [63]. Although this tumor vasculature normalization model is conceptually appealing, histologic examination of vasculature normalization in clinical setting to identify the optimized normalization window is limited in several aspects such as representative multiple small biopsies that would be hardly obtained for the global assessment of the solid tumor $[64,65]$.

Results from the preclinical studies pave the way for the use of anti-VEGF therapy in clinical trials. However, the results from the recent phase III clinical trials in breast cancer treatment using bevacizumab, a humanized monoclonal 
antibody against VEGF, are not as promising as in animal studies. A meta-analysis including five reported clinical trials involving metastatic breast cancer patients showed that the combined bevacizumab and chemotherapy arm had better objective response $(\mathrm{RR}=1.26,95 \% \mathrm{CI}=1.17,1.37)$ and progression-free survival $(\mathrm{HR}=0.70,95 \% \mathrm{CI}=0.60,0.82$ ) as compared to the chemotherapy-alone arm. However, no significant advantage was seen with the addition of bevacizumab as compared to the chemotherapy-alone arm for overall survival $(\mathrm{HR}=0.90,95 \% \mathrm{CI}=0.80,1.03)$ [66].

Two trials have published results and one has a report published recently for further inspection of the study design [83-85]. Although bevacizumab specifically blocks the VEGF-mediated pathways, all of these trials used bevacizumab as a general therapy given on a population basis without considering the specific molecular phenotype of the breast cancer. VEGF expression profile of the cancers was not investigated in the enrolled patients and the best methodology of evaluation has not yet been validated. Redundancy of other proangiogenic factors might also play important roles in advanced breast cancer. Consideration in these factors is needed to better stratify the patients who will most likely benefit from the VEGF-targeted therapy.

\section{Roles of Tumor-Associated Macrophages in Breast Cancer}

3.1. Macrophages Are Recruited into the Tumor. Infiltration of leukocytes in tumors was first recognized by Virchow in 1863 prompting him to postulate the link between the origin of cancer and inflammation [4]. This link, arbitrarily termed the extrinsic pathway, increases the risk of cancer development, exemplified by inflammatory conditions associated with malignancy such as ulcerative colitis linked to the development of colon cancer. In contrast, it is now evident that the intrinsic pathway, genetic alterations causing cancer without casual relationship to inflammatory processes, also leads to a protumor inflammatory microenvironment [86].

Among the heterogeneous populations of the leukocytic infiltrates, it has now been established that macrophages constitute the major proportion; for instance, up to $50 \%$ of cell mass in breast carcinoma is composed of macrophages [87]. These macrophages are called tumorassociated macrophages. They are mostly derived from the peripheral blood monocytes and recruited into the tumor by a wide range of chemokines and growth factors released by the tumor cells. Among these, CC chemokines, particularly CCL2 (formally monocyte chemoattractant protein1 or MCP-1) and CCL5, and growth factors such as colony-stimulating factor-1 (CSF-1) and vascular endothelial growth factor (VEGF) are strongly implicated in macrophage recruitment in various tumors including breast cancer [88].

3.2. Tumor-Associated Macrophages Are Polarized into M2 Phenotype in Tumor Microenvironment. The interaction between the tumor cells and the recruited tumor-associated macrophages has aroused much research study interest. The classical view of tumor-associated macrophages displaying antitumor response to destroy the tumor cells, similar to their pathophysiological response to microbial invasion, has however been confronted by a large number of studies that contradictorily showed their opposite protumor response. This paradoxical function of tumor-associated macrophages in relation to tumor is explained by the macrophage balance hypothesis where the outcomes of the tumorassociated macrophages depend on the polarization between two extremes of a continuum: M1 as proinflammatory and microbicidal/tumoricidal phenotype in contrast to M2 as anti-inflammatory and tumor-promoting phenotype [5].

Clinical studies across various human tumors exploring correlation between tumor-associated macrophage density and prognosis have shown constant strong inverse relationship in carcinomas of breast and cervix but a minority of conflicting results in prostate, stomach, and lung cancers [89]. These results suggest the importance of tumor microenvironment in tilting the macrophage balance and support largely the polarization of macrophage into protumor M2 phenotype by most tumors, including the breast carcinomas.

3.3. Tumor-Associated Macrophages Enhance Tumor Progression in Breast Cancer. In vitro and in vivo animal studies, especially the animal model of mammary tumor, have shed much light on the roles of tumor-associated macrophages in tumor progression. For instance, when a null mutation colony stimulating factor-1 gene was crossed into transgenic mice susceptible to mammary cancer due to the expression of the polyoma middle $\mathrm{T}$ antigen oncogene (PyMT mice), depletion of macrophages resulted in delayed tumor progression and tumor metastasis. In contrast, overexpression of CSF-1 gene resulted in increased macrophage infiltrates and in turn accelerated tumor progression and tumor metastasis [90].

Restricting the data pertinent to human breast cancer, the increased tumor-associated macrophages number correlates with high proliferative activity of the tumor cells as indicated by higher mitotic grade and Ki-67 labelling [6, 69, 76, 77, 81]. This association could be explained by the direct mitogenic stimulation of tumor cells by tumor-associated macrophages or indirect effect via stimulation of tumor angiogenesis by tumor-associated macrophages as discussed below. For the former possibility, tumor-associated macrophages indeed express and release a wide range of growth factors such as epidermal growth factor, basic fibroblast growth factor- 2 (FGF-2), transforming growth factor- $\beta$, VEGF, and plateletderived growth factor (PDGF) [91]. In particular, it has been shown that tumor-associated macrophages secrete epidermal growth factor, but the normal or malignant breast cancer cells do not [92]. Many breast cancers express epidermal growth factor receptor [93], which upon activation by this ligand leads to tumor survival and proliferation [94].

Furthermore, a paracrine loop between breast cancer cells and tumor-associated macrophages could promote the 
invasion of breast carcinoma via reciprocal stimulation because CSF-1 secreted by breast cancer cells recruits macrophages, and epidermal growth factor derived from the recruited macrophages promotes tumor cell motility [95]. In addition, tumor-associated macrophages produce enzymes and inhibitors, which regulate the digestion of the extracellular matrix such as matrix metalloproteinases (MMPs) [96] and urokinase-type plasminogen activator (uPA) [97]. Accordingly, degradation of the extracellular matrix by these macrophage proteases would facilitate the invasion of tumor cells into the stroma and hence metastasis $[89,98]$. This constitutes one of the mechanisms explaining the association of poor prognosis in breast cancer with higher macrophage density in clinical studies $[7,71,77,79]$.

\subsection{Tumor-Associated Macrophages Enhance Tumor Angio-} genesis in Breast Cancer. As discussed above, tumor angiogenesis is crucial for tumor progression. Tumor angiogenesis was initially thought to be induced only by tumor cells themselves; however, tumor-associated macrophages are indeed a major player in the regulation of tumor angiogenesis [99]. It is now evident that tumor-associated macrophages recruited into the tumor microenvironment are producers of a wide range of proangiogenic factors, including IL-1, VEGF, IL-8, bFGF, and TNF- $\alpha$ [100].

The process of activation and transformation of the tumor-associated macrophages into this proangiogenic phenotype is dependant on several tumor microenvironmental stress factors such as low oxygen, low $\mathrm{pH}$, and high lactate concentration [101]. Tumor hypoxia appears to be the major regulating factor. One study has shown that the median pO2 value in breast cancer was $30 \mathrm{mmHg}$ compared to $65 \mathrm{mmHg}$ in normal tissue and could be as low as between zero and $2.5 \mathrm{mmHg}$ [102]. Macrophages are attracted to these hypoxic areas $[70,73]$, and via the hypoxia-induced pathway, large numbers of genes encoding the proangiogenic factors are dramatically upregulated in the tumor-associated macrophages [103].

The first clinical study correlating tumor-associated macrophages and angiogenesis also came from a study on breast cancer. Significant correlation between the two was shown in addition to the prognostic value of tumorassociated macrophages, implying the crucial role of angiogenesis driven by tumor-associated macrophages in breast cancer progression [7]. Later clinical studies also produced similar findings $[76,77,79,81]$. In vivo animal study employing PyMT mice showed that the inhibition of macrophage maturation and infiltration into tumors delayed angiogenesis and tumor progression, providing evidence of causal role of tumor-associated macrophages in tumor angiogenesis [104].

3.5. Assessment of Tumor-Associated Macrophages in Breast Cancer by Immunohistochemistry Varies in Clinical Studies. Major findings in recent clinical studies exploring the link between the tumor-associated macrophages and other clinicopathological parameters in invasive breast carcinomas using immunohistochemistry are summarized in Table 2. These studies are generally agreeable in terms of association between the density of macrophages and clinicopathological parameters related to tumor progression. Besides, the significant association between density of macrophages and microvessel density implies the role of tumor-associated macrophages in tumor angiogenesis.

As shown in Table 2, in all but two studies, the antibody against CD68 was used to highlight the presence of macrophages. However, there is variation in the methods used to assess tumor-associated macrophages in these studies. Some studies used semiquantitative methods $[68,76$, $78,79]$ and others used quantitative methods with variation in selection of fields and count $[6,7,70-75,77,80-82]$. These variations in assessment method would give rise to minor discrepancies among the studies. In particular, no much attention was given to the location of tumorassociated macrophages in relation to breast carcinomas. It is known that the tumor-associated macrophages are attracted to hypoxic tumor areas, and angiogenesis is likely to be induced at these hypoxic areas. Most studies used the "hot spot" method to identify the areas of the highest number of tumor-associated macrophages $[7,70-75,77,80-82]$. These studies most probably have evaluated the tumor-associated macrophages at tumor margin where angiogenesis occurs, as opposed to tumor-associated macrophages within the tumor nest where information regarding their role is still lacking [105]. Evaluation by this "hot spot" methodology could also alleviate the concern about the confounding macrophages induced by biopsies prior to surgical resection of the tumor, as it is unlikely that a biopsy tract would induce accumulation of macrophages only at the tumor margin.

Given the many positive findings regarding the association of macrophages and breast tumor progression, a standardized evaluation method for assessing tumor-associated macrophages is therefore necessary to harmonize future research. A consensus of using "hot spot" method with particular reference to tumor-associated macrophages in tumor stroma would probably constitute such a template for examination.

3.6. Targeting Tumor-Associated Macrophages in Breast Cancer Represents an Attractive Approach. A plethora of growth factors, cytokines, and chemokines are employed in the process of recruitment, survival, activation and polarization, proangiogenic activity, and matrix remodeling of tumorassociated macrophages. These factors represent reasonable therapeutic targets [106]. For instance, in an experimental breast cancer model, antagonizing the chemokine CCL5 receptors expressed on the macrophages reduced the number of tumor-associated macrophages and slowed the tumor growth [107]. Using the anti-VEGF antibody to treat breast cancer xenografts, in addition to the inhibition of angiogenesis, infiltration of tumor-associated macrophages was also reduced. In these studies, tumor growth and distant metastases were inhibited [108, 109]. Although the contribution of reduction of tumor-associated macrophages to the observed results in these experimental studies has yet to be determined, pathological correlation in this aspect in the clinical trials employing anti-VEGF therapy would be of great interest. 
TABLE 2: Summary of clinical studies exploring the link between tumor-associated macrophages and other clinicopathological parameters in invasive breast carcinomas.

\begin{tabular}{ll}
\hline Tumor type & $\begin{array}{l}\text { Means of tumor-associated macrophages } \\
\text { assessment }\end{array}$ \\
\hline & $\begin{array}{l}\text { Macrophage marker: CD68 } \\
\text { Macrophage index was determined by 25-point } \\
\text { [7] invasive breast carcinomas }\end{array}$ \\
$\begin{array}{l}\text { Chalkey graticule as the mean of three "hot spot" } \\
\text { counts under 250x field }\end{array}$
\end{tabular}

75 invasive breast carcinomas
with lymphoplasmacytic
infiltrates [67]

75 invasive breast carcinomas $(50$ ductal, 9 lobular, 5 mixed, 5 tubular/cribriform, 1 mucinous) [68]

\section{Macrophage marker: CD11c \\ Macrophage was counted as percentage of total leukocyte infiltrate identified by CD 45 \\ Inflammation was classified as diffuse, perivascular, and perilobular on $\mathrm{H} \& \mathrm{E}$ and also using markers. Intensity was qualitatively graded as from 0 (absent) to 3 (marked) Macrophage marker: CD68}

120 invasive breast carcinomas (60\% ductal, 20\% lobular, 20\% others) [6]

Macrophage marker: CD68 (KP-1 antibody) Macrophages were counted in $40 \mathrm{hpf}(20 \mathrm{hpf}$ tumor cell zones and $20 \mathrm{hpf}$ stromal zones) and graded from weak $(<300)$ to intense $(>500)$

57 invasive breast carcinomas NOS (abstract) [69]

109 invasive breast carcinomas (ductal 88, lobular 8, others 13) [70]

26 invasive ductal carcinomas ( 13 cases $<5$ years, 13 cases $>5$ years' survival) [71]

\section{Macrophage marker: CD68}

Macrophage marker: CD68

Macrophage index was determined by 25-point Chalkey graticule as the mean of three "hot spot" counts under 250x field

\section{Macrophage marker: CD68}

Hot spots were identified under 100x, field and macrophages were counted in 5 hpf under 400x field

\section{Macrophage marker: CD68}

151 invasive ductal carcinomas [72] Macrophages were counted in 5 hot spots, and the mean of the highest three was determined (per $\mathrm{mm}^{2}$ )

\section{Macrophage marker: CD68}

96 invasive breast carcinomas (78 Macrophage index was determined by 25-point ductal, 7 lobular, 11 others) [73] Chalkey graticule as the mean of three "hot spot" counts under 250x field

Findings

(1) High macrophage index correlated with high vascular grade

(2) High macrophage index in poorly vascularized areas

(3) High macrophage index predicted reduced relapse-free and overall survival

(1) Macrophage predominance in leukocyte infiltrate correlated with high grade and c-erbB-2 expression

(1) In diffuse inflammation pattern, macrophage intensity predominated other cell types and was associated with high-grade, large tumor size, tumor necrosis, and c-erbB-2 expression

(2) Intensity of diffuse inflammation but not macrophage correlated with vascularity

(1) Intensity of macrophage was higher in node-negative tumors

(2) Intratumoral macrophage infiltration correlated with high tumor grade, absence of ER, and high mitotic grade

(1) Tumor-associated macrophages correlated with mitotic activity index

(1) Higher macrophage index associated with necrosis

(1) Higher macrophage count in poor prognosis group

(1) High macrophage count correlated with high levels of macrophage chemoattractant protein-1 and thymidine phosphorylase in breast cancer by ELISA

(2) High level of macrophage chemoattractant protein-1 had worsened relapse-free survival

(1) Macrophage index correlated with high VEGF and EGFR expression

(2) In EGFR-negative cases, high VEGF correlated with increased macrophage index, high grade, presence of necrosis, and increased tumor p53 expression

(3) No significant prognostic value of VEGF

\section{Macrophage marker: CD68}

Macrophage index was determined by 25-point

24 invasive breast carcinomas (12 Chalkey graticule or by absolute count as the ductal, 12 lobular) [74] mean of five VEGF positive areas under 200x field. In VEGF-negative areas, 5 most or least vascularized areas were chosen

230 invasive ductal carcinomas [75]
Macrophage marker: CD68 macrophages were counted in 5 hot spots, and the mean of the highest three was determined (per $\left.\mathrm{mm}^{2}\right)$. Graded from $0\left(<50 / \mathrm{mm}^{2}\right)$ to $2\left(>100 \mathrm{~mm}^{2}\right)$
(1) Macrophage count was higher in less vascularized areas

(1) High macrophage count showed a tendency of correlation with high level of tumoral macrophage chemoattractant protein-1 by immunohistochemistry $(P=.089)$.

(2) High level of tumoral macrophage chemoattractant protein-1 showed a tendency of correlation with high microvessel density grade $(P=.087)$ 
TABle 2: Continued.

\begin{tabular}{|c|c|c|}
\hline Tumor type & $\begin{array}{l}\text { Means of tumor-associated macrophages } \\
\text { assessment }\end{array}$ & Findings \\
\hline $\begin{array}{l}97 \text { invasive ductal carcinomas } \\
{[76]}\end{array}$ & $\begin{array}{l}\text { Macrophage marker: CD68 } \\
\text { Macrophages were semiqualitatively graded as } 1= \\
\text { no macrophages, } 2=\text { small foci of macrophages, } 3 \\
=\text { large foci of macrophages } 4=\text { diffuse } \\
\text { macrophages infiltration in tumor stroma }\end{array}$ & $\begin{array}{l}\text { (1) Higher macrophage grade associated with } \\
\text { higher VEGF expression, higher microvessel } \\
\text { density, and higher mitotic activity index }\end{array}$ \\
\hline $\begin{array}{l}249 \text { invasive ductal carcinomas } \\
\text { (abstract) [77] }\end{array}$ & $\begin{array}{l}\text { Macrophage density was assessed as average } \\
\text { density of three hot spots at a magnification of } \\
400 \mathrm{x}\end{array}$ & $\begin{array}{l}\text { (1) Macrophage density significantly correlated } \\
\text { with both the VEGF expression and MVD } \\
\text { (2) Macrophage density was associated with the } \\
\text { nuclear grade, estrogen receptor status, and } \\
\text { MIB-1 count } \\
\text { (3) Patients with a high macrophage density had a } \\
\text { significantly worse disease-free survival prognosis } \\
\text { than those with a low density }\end{array}$ \\
\hline
\end{tabular}

Macrophage marker: CD68

Macrophages were semiqualitatively graded as $1=$

97 breast carcinomas [78]

no macrophages, 2 = small and large foci of

macrophages, 3 = diffuse macrophages infiltration in tumor stroma
(1) Macrophage grade was not correlated with tumor chemoattractant protein-1

(1) Higher macrophages in invasive ductal carcinomas compared to invasive lobular carcinomas

Macrophage marker: HAM56 antibody

78 invasive breast carcinomas ( 48 ductal, 30 lobular) [79]

Macrophages were semiqualitatively graded as $1=$ no macrophages, 2 = small foci of macrophages, 3 $=$ large foci of macrophages, $4=$ diffuse macrophages infiltration in tumor stroma grade correlated with tumor size, lymph node tumor grade
(2) In invasive ductal carcinomas, macrophage metastasis, stage, microvessel density, VEGF, and

(3) In invasive ductal carcinomas, macrophage grade and clinical stage were predictive in disease-free survival rate

(1) Higher macrophage count associated with high tumor grade, p53 expression, absence of ER, high VEGF expression in macrophage, and postsurgical serum VEGF level

Macrophages were counted in 5 consecutive 400x fields in areas identified as "hot spots" under 100x

Macrophage marker: CD68

Macrophages were counted using point counting method (expressed as percentage of volume occupied by a component out of total volume) using a 100-point ocular grid counting at $400 \mathrm{x}$ field over 30 fields and were grouped tertiles

\section{Macrophage marker: CD68}

Macrophages were counted as mean of the 3

128 invasive ductal carcinomas [82]
(1) High tertile percentage of macrophage correlated with high tumor grade, high Ki-67 labelling, absence of hormonal receptors, high microvessel density, high CD4 and CD8 count

(1) Macrophage count correlated with stromal chemoattractant protein-1

(2) Stromal chemoattractant protein-1 correlated with lymphatic invasion and predicted worsened relapse-free survival

\section{Conclusion}

In conclusion, the salient points regarding trilateral relationship among breast cancer cells, tumor-associated macrophages, and tumor angiogenesis are

(1) breast cancer progression is dependent on tumor angiogenesis,

(2) breast cancer cells are able to regulate tumor angiogenesis via production of proangiogenic factors,

(3) tumor-associated macrophages have emerged as a major player in regulating breast cancer progression,
(4) as a major regulatory mechanism in tumor progression, tumor-associated macrophages enhance breast tumor angiogenesis,

(5) breast cancer progression involves reciprocal interactions between breast cancer cells and tumorassociated macrophages.

At the tissue level, the assessment of the relationship between these three compartments is feasible by histopathological examination coupled with immunohistochemistry. Despite its limitations, microvessel density has been widely 
used as a surrogate marker for tumor angiogenesis. Establishment of a validated immunohistochemical evaluation of proangiogenic factors produced by breast cancer is essential. Information regarding expression profile of proangiogenic factors might help to stratify patients receiving antiangiogenic therapy. Tumor-associated macrophage density can be graded in similar manner as microvessel density evaluation. Assessment in this regard would possibly constitute another important item in histopathological examination for prognostication, considering therapeutic advances targeting tumor-associated macrophages.

\section{Conflict of Interests}

All authors have no conflict of interests.

\section{References}

[1] S. Banerjee, M. Dowsett, A. Ashworth, and L. A. Martin, "Mechanisms of disease: angiogenesis and the management of breast cancer," Nature Clinical Practice Oncology, vol. 4, no. 9, pp. 536-550, 2007.

[2] M. Schmitt, N. Harbeck, and J. S. Ross, "Breast cancer and angiogenesis," in Molecular Oncology of Breast Cancer, J. S. Ross and G. N. Hortobagyi, Eds., pp. 289-312, Jones and Bartlett Publishers, Sudbury, Mass, USA, 1st edition, 2005.

[3] B. Uzzan, P. Nicolas, M. Cucherat, and G. Y. Perret, "Microvessel density as a prognostic factor in women with breast cancer: a systematic review of the literature and metaanalysis," Cancer Research, vol. 64, no. 9, pp. 2941-2955, 2004.

[4] F. Balkwill and A. Mantovani, "Inflammation and cancer: back to Virchow?" The Lancet, vol. 357, no. 9255, pp. 539545, 2001.

[5] A. Mantovani, S. Sozzani, M. Locati, P. Allavena, and A. Sica, "Macrophage polarization: tumor-associated macrophages as a paradigm for polarized M2 mononuclear phagocytes," Trends in Immunology, vol. 23, no. 11, pp. 549-555, 2002.

[6] N. Volodko, A. Reiner, M. Rudas, and R. Jakesz, "Tumourassociated macrophages in breast cancer and their prognostic correlations," Breast, vol. 7, no. 2, pp. 99-105, 1998.

[7] R. D. Leek, C. E. Lewis, R. Whitehouse, M. Greenall, J. Clarke, and A. L. Harris, "Association of macrophage infiltration with angiogenesis and prognosis in invasive breast carcinoma," Cancer Research, vol. 56, no. 20, pp. 4625-4629, 1996.

[8] D. Hanahan and R. A. Weinberg, "The hallmarks of cancer," Cell, vol. 100, no. 1, pp. 57-70, 2000.

[9] J. Folkman, "Role of angiogenesis in tumor growth and metastasis," Seminars in Oncology, vol. 29, no. 6, pp. 15-18, 2002.

[10] J. Folkman, "History of angiogenesis," in Angiogenesis: An Integrative Approach from Science to Medicine, W. D. Figg and J. Folkman, Eds., pp. 1-14, Springer, New York, NY, USA, 2008.

[11] M. Papetti and I. M. Herman, "Mechanisms of normal and tumor-derived angiogenesis," American Journal of Physiology, vol. 282, no. 5, pp. C947-C970, 2002.

[12] I. P. Torres Filho, M. Leunig, F. Yuan, M. Intaglietta, and R. K. Jain, "Noninvasive measurement of microvascular and interstitial oxygen profiles in a human tumor in SCID mice," Proceedings of the National Academy of Sciences of the United States of America, vol. 91, no. 6, pp. 2081-2085, 1994.
[13] D. Fukumura and R. K. Jain, "Tumor microvasculature and microenvironment: targets for anti-angiogenesis and normalization," Microvascular Research, vol. 74, no. 2-3, pp. 72-84, 2007.

[14] R. R. Langley and I. J. Fidler, “Tumor cell-organ microenvironment interactions in the pathogenesis of cancer metastasis," Endocrine Reviews, vol. 28, no. 3, pp. 297-321, 2007.

[15] E. Favaro, A. Amadori, and S. Indraccolo, "Cellular interactions in the vascular niche: implications in the regulation of tumor dormancy," APMIS, vol. 116, no. 7-8, pp. 648-659, 2008.

[16] D. Ribatti, B. Nico, E. Crivellato, A. M. Roccaro, and A. Vacca, "The history of the angiogenic switch concept," Leukemia, vol. 21, no. 1, pp. 44-52, 2007.

[17] R. W. C. Pang and R. T. P. Poon, "Clinical implications of angiogenesis in cancers," Vascular Health and Risk Management, vol. 2, no. 2, pp. 97-108, 2006.

[18] J. E. Bluff, S. R. Menakuru, S. S. Cross et al., "Angiogenesis is associated with the onset of hyperplasia in human ductal breast disease," British Journal of Cancer, vol. 101, no. 4, pp. 666-672, 2009.

[19] P. Viacava, A. G. Naccarato, G. Bocci et al., "Angiogenesis and VEGF expression in pre-invasive lesions of the human breast," Journal of Pathology, vol. 204, no. 2, pp. 140-146, 2004.

[20] P. M. Carpenter, W.-P. Chen, A. Mendez, C. E. McLaren, and M. Y. Su, "Angiogenesis in the progression of breast ductal proliferations," International Journal of Surgical Pathology. In press.

[21] M. Relf, S. Lejeune, P. A. E. Scott et al., "Expression of the angiogenic factors vascular endothelial cell growth factor, acidic and basic fibroblast growth factor, tumor growth factor $\beta$-1, platelet-derived endothelial cell growth factor, placenta growth factor, and pleiotrophin in human primary breast cancer and its relation to angiogenesis," Cancer Research, vol. 57, no. 5, pp. 963-969, 1997.

[22] L. Rydén, K. Jirström, P. O. Bendahl et al., "Tumor-specific expression of vascular endothelial growth factor receptor 2 but not vascular endothelial growth factor or human epidermal growth factor receptor 2 is associated with impaired response to adjuvant tamoxifen in premenopausal breast cancer," Journal of Clinical Oncology, vol. 23, no. 21, pp. 46954704, 2005.

[23] S. F. Schoppmann, D. Tamandl, L. Roberts et al., "HER2/neu expression correlates with vascular endothelial growth factor-C and lymphangiogenesis in lymph node-positive breast cancer," Annals of Oncology, vol. 21, no. 5, pp. 955-960, 2009.

[24] L. Rydén, K. Jirstrom, M. Haglund, O. Stal, and M. Fernö, "Epidermal growth factor receptor and vascular endothelial growth factor receptor 2 are specific biomarkers in triplenegative breast cancer. Results from a controlled randomized trial with long-term follow-up," Breast Cancer Research and Treatment, vol. 120, no. 2, pp. 491-498, 2010.

[25] L. Rydén, D. Grabau, F. Schaffner, P. E. Jönsson, W. Ruf, and M. Belting, "Evidence for tissue factor phosphorylation and its correlation with protease-activated receptor expression and the prognosis of primary breast cancer," International Journal of Cancer, vol. 126, no. 10, pp. 2330-2340, 2010.

[26] I. Gisterek, R. Matkowski, E. Suder et al., "Correlation between hepatocyte growth factor receptor and vascular endothelial growth factor-A in breast carcinoma," Folia Histochemica et Cytobiologica, vol. 48, no. 1, pp. 78-83, 2010. 
[27] X. S. Tian, M. H. Cong, W. H. Zhou, J. Zhu, Y. Z. Chen, and Q. Liu, "Clinicopathologic and prognostic characteristics of triple-negative breast cancer," Onkologie, vol. 31, no. 11, pp. 610-614, 2008.

[28] Y. Nieto, J. Woods, F. Nawaz et al., "Prognostic analysis of tumour angiogenesis, determined by microvessel density and expression of vascular endothelial growth factor, in highrisk primary breast cancer patients treated with high-dose chemotherapy," British Journal of Cancer, vol. 97, no. 3, pp. 391-397, 2007.

[29] K. Byrnes, S. White, Q. Chu et al., "High eIF4E, VEGF, and microvessel density in stage I to III breast cancer," Annals of Surgery, vol. 243, no. 5, pp. 684-691, 2006.

[30] S. F. Schoppmann, A. Fenzl, M. Schindl et al., "Hypoxia inducible factor- $1 \alpha$ correlates with VEGF-C expression and lymphangiogenesis in breast cancer," Breast Cancer Research and Treatment, vol. 99, no. 2, pp. 135-141, 2006.

[31] I. Kostopoulos, P. Arapantoni-Dadioti, H. Gogas et al., "Evaluation of the prognostic value of HER-2 and VEGF in breast cancer patients participating in a randomized study with dose-dense sequential adjuvant chemotherapy," Breast Cancer Research and Treatment, vol. 96, no. 3, pp. 251-261, 2006.

[32] S. Yavuz, S. Paydas, U. Disel, S. Zorludemir, and S. Erdogan, "VEGF-C expression in breast cancer: clinical importance," Advances in Therapy, vol. 22, no. 4, pp. 368-380, 2005.

[33] O. Watanabe, J. Kinoshita, T. Shimizu et al., "Expression of a CD44 variant and VEGF-C and the implications for lymphatic metastasis and long-term prognosis of human breast cancer," Journal of Experimental and Clinical Cancer Research, vol. 24, no. 1, pp. 75-82, 2005.

[34] M. J. Currie, V. Hanrahan, S. P. Gunningham et al., "Expression of vascular endothelial growth factor D is associated with hypoxia inducible factor (HIF- $1 \alpha$ ) and the HIF- $1 \alpha$ target gene DEC1, but not lymph node metastasis in primary human breast carcinomas," Journal of Clinical Pathology, vol. 57, no. 8, pp. 829-834, 2004.

[35] V. Ludovini, A. Sidoni, L. Pistola et al., "Evaluation of the prognostic role of vascular endothelial growth factor and microvessel density in stages I and II breast cancer patients," Breast Cancer Research and Treatment, vol. 81, no. 2, pp. 159168, 2003.

[36] J. S. Lee, H. S. Kim, J. J. Jung, Y. B. Kim, M. C. Lee, and C. S. Park, "Expression of vascular endothelial growth factor in invasive ductal carcinoma of the breast and the relation to angiogenesis and p53 and HER-2/neu protein expression," Applied Immunohistochemistry \& Molecular Morphology, vol. 10, no. 4, pp. 289-295, 2002.

[37] F. De Paola, A. M. Granato, E. Scarpi et al., "Vascular endothelial growth factor and prognosis in patients with node-negative breast cancer," International Journal of Cancer, vol. 98, no. 2, pp. 228-233, 2002.

[38] Y. Gu, X. Qi, and S. Guo, "Lymphangiogenesis induced by VEGF-C and VEGF-D promotes metastasis and a poor outcome in breast carcinoma: a retrospective study of 61 cases," Clinical and Experimental Metastasis, vol. 25, no. 7, pp. 717-725, 2008.

[39] X. H. Zhang, D. P. Huang, G. L. Guo et al., "Coexpression of VEGF-C and COX-2 and its association with lymphangiogenesis in human breast cancer," BMC Cancer, vol. 8, article 4, 2008.

[40] R. A. A. Mohammed, A. Green, S. El-Shikh, E. C. Paish, I. O. Ellis, and S. G. Martin, "Prognostic significance of vascular endothelial cell growth factors -A, -C and -D in breast cancer and their relationship with angio- and lymphangiogenesis," British Journal of Cancer, vol. 96, no. 7, pp. 1092-1100, 2007.

[41] E. Mylona, P. Alexandrou, I. Giannopoulou et al., "The prognostic value of vascular endothelial growth factors (VEGFs)-A and -B and their receptor, VEGFR-1, in invasive breast carcinoma," Gynecologic Oncology, vol. 104, no. 3, pp. 557-563, 2007.

[42] E. Mylona, P. Alexandrou, A. Mpakali et al., "Clinicopathological and prognostic significance of vascular endothelial growth factors (VEGF)-C and -D and VEGF receptor 3 in invasive breast carcinoma," European Journal of Surgical Oncology, vol. 33, no. 3, pp. 294-300, 2007.

[43] S. Zhou, G. P. Wang, C. Liu, and M. Zhou, "Eukaryotic initiation factor $4 \mathrm{E}$ (elF4E) and angiogenesis: prognostic markers for breast cancer," BMC Cancer, vol. 6, article 231, 2006.

[44] L. Rydén, M. Stendahl, H. Jonsson, S. Emdin, N. O. Bengtsson, and G. Landberg, "Tumor-specific VEGF-A and VEGFR2 in postmenopausal breast cancer patients with long-term follow-up. Implication of a link between VEGF pathway and tamoxifen response," Breast Cancer Research and Treatment, vol. 89, no. 2, pp. 135-143, 2005.

[45] Y. Nakamura, H. Yasuoka, M. Tsujimoto et al., "Prognostic significance of vascular endothelial growth factor D in breast carcinoma with long-term follow-up," Clinical Cancer Research, vol. 9, no. 2, pp. 716-721, 2003.

[46] Y. Nakamura, H. Yasuoka, M. Tsujimoto et al., "Clinicopathological significance of vascular endothelial growth factor-C in breast carcinoma with long-term follow-up," Modern Pathology, vol. 16, no. 4, pp. 309-314, 2003.

[47] W. Yang, K. Klos, Y. Yang, T. L. Smith, D. Shi, and D. Yu, "ErbB2 overexpression correlates with increased expression of vascular endothelial growth factors A, C, and D in human breast carcinoma," Cancer, vol. 94, no. 11, pp. 2855-2861, 2002.

[48] J. Kinoshita, K. Kitamura, A. Kabashima, H. Saeki, S. Tanaka, and K. Sugimachi, "Clinical significance of vascular endothelial growth factor-C (VEGF-C) in breast cancer," Breast Cancer Research and Treatment, vol. 66, no. 2, pp. 159164, 2001.

[49] N. Weidner, J. P. Semple, W. R. Welch, and J. Folkman, "Tumor angiogenesis and metastasis-correlation in invasive breast carcinoma," The New England Journal of Medicine, vol. 324, no. 1, pp. 1-8, 1991.

[50] B. V. Offersen, M. Borre, and J. Overgaard, "Quantification of angiogenesis as a prognostic marker in human carcinomas: a critical evaluation of histopathological methods for estimation of vascular density," European Journal of Cancer, vol. 39, no. 7, pp. 881-890, 2003.

[51] N. B. Teo, B. S. Shoker, C. Jarvis, L. Martin, J. P. Sloane, and C. Holcombe, "Angiogenesis and invasive recurrence in ductal carcinoma in situ of the breast," European Journal of Cancer, vol. 39, no. 1, pp. 38-44, 2003.

[52] G. Gasparini, S. B. Fox, P. Verderio et al., "Determination of angiogenesis adds information to estrogen receptor status in predicting the efficacy of adjuvant tamoxifen in nodepositive breast cancer patients," Clinical Cancer Research, vol. 2, no. 7, pp. 1191-1198, 1996.

[53] I. H. Benoy, R. Salgado, H. Elst et al., "Relative microvessel area of the primary tumour, and not lymph node status, predicts the presence of bone marrow micrometastases detected by reverse transcriptase polymerase chain reaction in patients with clinically non-metastatic breast cancer," Breast Cancer Research, vol. 7, no. 2, pp. R210-219, 2005. 
[54] X. D. Xie, S. X. Qu, Z. Z. Liu, F. Zhang, and Z. D. Zheng, "Study on relationship between angiogenesis and micrometastases of peripheral blood in breast cancer," Journal of Cancer Research and Clinical Oncology, vol. 135, no. 3, pp. 413-419, 2009.

[55] S. B. Fox, R. D. Leek, J. Bliss et al., "Association of tumor angiogenesis with bone marrow micrometastases in breast cancer patients," Journal of the National Cancer Institute, vol. 89, no. 14, pp. 1044-1049, 1997.

[56] L. Martin, B. Green, C. Renshaw et al., "Examining the technique of angiogenesis assessment in invasive breast cancer," British Journal of Cancer, vol. 76, no. 8, pp. 1046$1054,1997$.

[57] S. B. Fox, "Quantitative angiogenesis in breast cancer," in Breast Cancer Researh Protocols, S. A. Brooks and A. Harris, Eds., pp. 161-187, Humana Press, Totowa, NJ, USA, 2006.

[58] P. B. Vermeulen, G. Gasparini, S. B. Fox et al., "Second international consensus on the methodology and criteria of evaluation of angiogenesis quantification in solid human tumours," European Journal of Cancer, vol. 38, no. 12, pp. 1564-1579, 2002.

[59] S. Sharma, M. C. Sharma, and C. Sarkar, "Morphology of angiogenesis in human cancer: a conceptual overview, histoprognostic perspective and significance of neoangiogenesis," Histopathology, vol. 46, no. 5, pp. 481-489, 2005.

[60] H. P. Dhakal, A. Bassarova, B. Naume et al., "Breast carcinoma vascularity: a comparison of manual microvessel count and Chalkley count," Histology and histopathology, vol. 24, no. 8, pp. 1049-1059, 2009.

[61] S. Hansen, F. B. Sørensen, W. Vach, D. A. Grabau, M. Bak, and C. Rose, "Microvessel density compared with the Chalkley count in a prognostic study of angiogenesis in breast cancer patients," Histopathology, vol. 44, no. 5, pp. 428-436, 2004.

[62] N. Ferrara, "Vascular endothelial growth factor: basic science and clinical progress," Endocrine Reviews, vol. 25, no. 4, pp. 581-611, 2004.

[63] H. P. Gerber and N. Ferrara, "Pharmacology and pharmacodynamics of bevacizumab as monotherapy or in combination with cytotoxic therapy in preclinical studies," Cancer Research, vol. 65, no. 3, pp. 671-680, 2005.

[64] R. K. Jain, "Normalizing tumor vasculature with antiangiogenic therapy: a new paradigm for combination therapy," Nature Medicine, vol. 7, no. 9, pp. 987-989, 2001.

[65] R. K. Jain, "Normalization of tumor vasculature: an emerging concept in antiangiogenic therapy," Science, vol. 307, no. 5706, pp. 58-62, 2005.

[66] A. Valachis, N. P. Polyzos, N. A. Patsopoulos, V. Georgoulias, D. Mavroudis, and D. Mauri, "Bevacizumab in metastatic breast cancer: a meta-analysis of randomized controlled trials," Breast Cancer Research and Treatment, vol. 122, no. 1, pp. 1-7, 2010.

[67] S. M. Pupa, R. Bufalino, A. M. Invernizzi et al., "Macrophage infiltrate and prognosis in c-erbB-2-overexpressing breast carcinomas," Journal of Clinical Oncology, vol. 14, no. 1, pp. 85-94, 1996.

[68] A. H. S. Lee, L. C. Happerfield, L. G. Bobrow, and R. R. Millis, "Angiogenesis and inflammation in invasive carcinoma of the breast," Journal of Clinical Pathology, vol. 50, no. 8, pp. 669673, 1997.

[69] N. Jonjić, T. Valković, K. Lučin et al., "Comparison of microvessel density with tumor associated macrophages in invasive breast carcinoma," Anticancer Research, vol. 18, no. 5 B, pp. 3767-3770, 1998.
[70] R. D. Leek, R. J. Landers, A. L. Harris, and C. E. Lewis, "Necrosis correlates with high vascular density and focal macrophage infiltration in invasive carcinoma of the breast," British Journal of Cancer, vol. 79, no. 5-6, pp. 991-995, 1999.

[71] V. Goede, L. Brogelli, M. Ziche, and H. G. Augustin, "Induction of inflammatory angiogenesis by monocyte chemoattractant protein-1," International Journal of Cancer, vol. 82, no. 5, pp. 765-770, 1999.

[72] T. Ueno, M. Toi, H. Saji et al., "Significance of macrophage chemoattractant protein-1 in macrophage recruitment, angiogenesis, and survival in human breast cancer," Clinical Cancer Research, vol. 6, no. 8, pp. 3282-3289, 2000.

[73] R. D. Leek, N. C. Hunt, R. J. Landers, C. E. Lewis, J. A. Royds, and A. L. Harris, "Macrophage infiltration is associated with VEGF and EGFR expression in breast cancer," Journal of Pathology, vol. 190, no. 4, pp. 430-436, 2000.

[74] J. S. Lewis, R. J. Landers, J. C. E. Underwood, A. L. Harris, and C. E. Lewis, "Expression of vascular endothelial growth factor by macrophages is up-regulated in poorly vascularized areas of breast carcinomas," Journal of Pathology, vol. 192, no. 2, pp. 150-158, 2000.

[75] H. Saji, M. Koike, T. Yamori et al., "Significant correlation of monocyte chemoattractant protein-1 expression with neovascularization and progression of breast carcinoma," Cancer, vol. 92, no. 5, pp. 1085-1091, 2001.

[76] T. Valković, F. Dobrila, M. Melato, F. Sasso, C. Rizzardi, and N. Jonjić, "Correlation between vascular endothelial growth factor, angiogenesis, and tumor-associated macrophages in invasive ductal breast carcinoma," Virchows Archiv, vol. 440, no. 6, pp. 583-588, 2002.

[77] S. Tsutsui, K. Yasuda, K. Suzuki, K. Tahara, H. Higashi, and S. Era, "Macrophage infiltration and its prognostic implications in breast cancer: the relationship with VEGF expression and microvessel density," Oncology Reports, vol. 14, no. 2, pp. 425-431, 2005.

[78] T. Valković, D. Fučkar, S. Štifter et al., "Macrophage level is not affected by monocyte chemotactic protein-1 in invasive ductal breast carcinoma," Journal of Cancer Research and Clinical Oncology, vol. 131, no. 7, pp. 453-458, 2005.

[79] F. Bolat, F. Kayaselcuk, T. Z. Nursal, M. C. Yagmurdur, N. Bal, and B. Demirhan, "Microvessel density, VEGF expression, and tumor-associated macrophages in breast tumors: correlations with prognostic parameters," Journal of Experimental and Clinical Cancer Research, vol. 25, no. 3, pp. 365-372, 2006.

[80] L. Vicioso, F. J. Gonzalez, M. Alvarez et al., "Elevated serum levels of vascular endothelial growth factor are associated with tumor-associated macrophages in primary breast cancer," American Journal of Clinical Pathology, vol. 125, no. 1, pp. 111-118, 2006.

[81] A. M. Al Murri, M. Hilmy, J. Bell et al., "The relationship between the systemic inflammatory response, tumour proliferative activity, T-lymphocytic and macrophage infiltration, microvessel density and survival in patients with primary operable breast cancer," British Journal of Cancer, vol. 99, no. 7, pp. 1013-1019, 2008

[82] H. Fujimoto, T. Sangai, G. Ishii et al., "Stromal MCP-1 in mammary tumors induces tumor-associated macrophage infiltration and contributes to tumor progression," International Journal of Cancer, vol. 125, no. 6, pp. 1276-1284, 2009.

[83] D. W. Miles, A. Chan, L. Y. Dirix et al., "Phase III study of bevacizumab plus docetaxel compared with placebo plus docetaxel for the first-line treatment of human epidermal 
growth factor receptor 2-negative metastatic breast cancer," Journal of Clinical Oncology, vol. 28, no. 20, pp. 3239-3247, 2010.

[84] K. Miller, M. Wang, J. Gralow et al., "Paclitaxel plus bevacizumab versus paclitaxel alone for metastatic breast cancer," The New England Journal of Medicine, vol. 357, no. 26, pp. 2666-2676, 2007.

[85] K. D. Miller, L. I. Chap, F. A. Holmes et al., "Randomized phase III trial of capecitabine compared with bevacizumab plus capecitabine in patients with previously treated metastatic breast cancer," Journal of Clinical Oncology, vol. 23, no. 4, pp. 792-799, 2005.

[86] P. Allavena, A. Sica, C. Garlanda, and A. Mantovani, "The Yin-Yang of tumor-associated macrophages in neoplastic progression and immune surveillance," Immunological Reviews, vol. 222, no. 1, pp. 155-161, 2008.

[87] C. E. Lewis, R. Leek, A. Harris et al., "Cytokine regulation of angiogenesis in breast cancer: the role of tumor-associated macrophages," Journal of Leukocyte Biology, vol. 57, no. 5, pp. 747-751, 1995.

[88] C. Murdoch, A. Giannoudis, and C. E. Lewis, "Mechanisms regulating the recruitment of macrophages into hypoxic areas of tumors and other ischemic tissues," Blood, vol. 104, no. 8, pp. 2224-2234, 2004.

[89] L. Bingle, N. J. Brown, and C. E. Lewis, "The role of tumourassociated macrophages in tumour progression: implications for new anticancer therapies," Journal of Pathology, vol. 196, no. 3, pp. 254-265, 2002.

[90] E. Y. Lin, A. V. Nguyen, R. G. Russell, and J. W. Pollard, "Colony-stimulating factor 1 promotes progression of mammary tumors to malignancy," Journal of Experimental Medicine, vol. 193, no. 6, pp. 727-739, 2001.

[91] D. Ribatti, B. Nico, E. Crivellato, and A. Vacca, "Macrophages and tumor angiogenesis," Leukemia, vol. 21, no. 10, pp. 2085 2089, 2007.

[92] C. O’Sullivan, C. E. Lewis, A. L. Harris, and J. McGee O'D, "Secretion of epidermal growth factor by macrophages associated with breast carcinoma," The Lancet, vol. 342, no. 8864, pp. 148-149, 1993.

[93] S. K. Chan, M. E. Hill, and W. J. Gullick, "The role of the epidermal growth factor receptor in breast cancer," Journal of Mammary Gland Biology and Neoplasia, vol. 11, no. 1, pp. 3-11, 2006.

[94] N. E. Hynes and H. A. Lane, "ERBB receptors and cancer: the complexity of targeted inhibitors," Nature Reviews Cancer, vol. 5, no. 5, pp. 341-354, 2005.

[95] S. Goswami, E. Sahai, J. B. Wyckoff et al., "Macrophages promote the invasion of breast carcinoma cells via a colonystimulating factor-1/epidermal growth factor paracrine loop," Cancer Research, vol. 65, no. 12, pp. 5278-5283, 2005.

[96] T. Hagemann, S. C. Robinson, M. Schulz, L. Trümper, F. R. Balkwill, and C. Binder, "Enhanced invasiveness of breast cancer cell lines upon co-cultivation with macrophages is due to TNF- $\alpha$ dependent up-regulation of matrix metalloproteases," Carcinogenesis, vol. 25, no. 8, pp. 1543-1549, 2004.

[97] R. Hildenbrand, A. Schaaf, A. Dorn-Beineke et al., "Tumor stroma is the predominant uPA-, uPAR-, PAI-1-expressing tissue in human breast cancer: prognostic impact," Histology and Histopathology, vol. 24, no. 7, pp. 869-877, 2009.

[98] J. W. Pollard, "Tumour-educated macrophages promote tumour progression and metastasis," Nature Reviews Cancer, vol. 4, no. 1, pp. 71-78, 2004.
[99] C. Sunderkotter, K. Steinbrink, M. Goebeler, R. Bhardwaj, and C. Sorg, "Macrophages and angiogenesis," Journal of Leukocyte Biology, vol. 55, no. 3, pp. 410-422, 1994.

[100] A. E. M. Dirkx, M. G. A. Oude Egbrink, J. Wagstaff, and A. W. Griffioen, "Monocyte/macrophage infiltration in tumors: modulators of angiogenesis," Journal of Leukocyte Biology, vol. 80, no. 6, pp. 1183-1196, 2006.

[101] M. Crowther, N. J. Brown, E. T. Bishop, and C. E. Lewis, "Microenvironmental influence on macrophage regulation of angiogenesis in wounds and malignant tumors," Journal of Leukocyte Biology, vol. 70, no. 4, pp. 478-490, 2001.

[102] P. Vaupel, K. Schlenger, C. Knoop, and M. Hockel, "Oxygenation of human tumors: evaluation of tissue oxygen distribution in breast cancers by computerized $\mathrm{O}_{2}$ tension measurements," Cancer Research, vol. 51, no. 12, pp. 33163322, 1991.

[103] C. Murdoch and C. E. Lewis, "Macrophage migration and gene expression in response to tumor hypoxia," International Journal of Cancer, vol. 117, no. 5, pp. 701-708, 2005.

[104] E. Y. Lin, J. F. Li, L. Gnatovskiy et al., "Macrophages regulate the angiogenic switch in a mouse model of breast cancer," Cancer Research, vol. 66, no. 23, pp. 11238-11246, 2006.

[105] S. Ohno, H. Inagawa, G.-I. Soma, and N. Nagasue, "Role of tumor-associated macrophage in malignant tumors: should the location of the infiltrated macrophages be taken into account during evaluation?" Anticancer Research, vol. 22, no. 6 C, pp. 4269-4275, 2002.

[106] A. Sica, P. Allavena, and A. Mantovani, "Cancer related inflammation: the macrophage connection," Cancer Letters, vol. 267, no. 2, pp. 204-215, 2008.

[107] S. C. Robinson, K. A. Scott, J. L. Wilson, R. G. Thompson, A. E. I. Proudfoot, and F. R. Balkwill, "A chemokine receptor antagonist inhibits experimental breast tumor growth," Cancer Research, vol. 63, no. 23, pp. 8360-8365, 2003.

[108] B. Whitehurst, M. J. Flister, J. Bagaitkar et al., "Anti-VEGFA therapy reduces lymphatic vessel density and expression of VEGFR-3 in an orthotopic breast tumor model," International Journal of Cancer, vol. 121, no. 10, pp. 2181-2191, 2007.

[109] C. L. Roland, S. P. Dineen, K. D. Lynn et al., "Inhibition of vascular endothelial growth factor reduces angiogenesis and modulates immune cell infiltration of orthotopic breast cancer xenografts," Molecular Cancer Therapeutics, vol. 8, no. 7, pp. 1761-1771, 2009. 


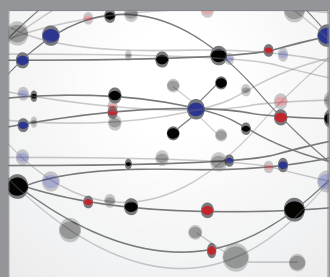

The Scientific World Journal
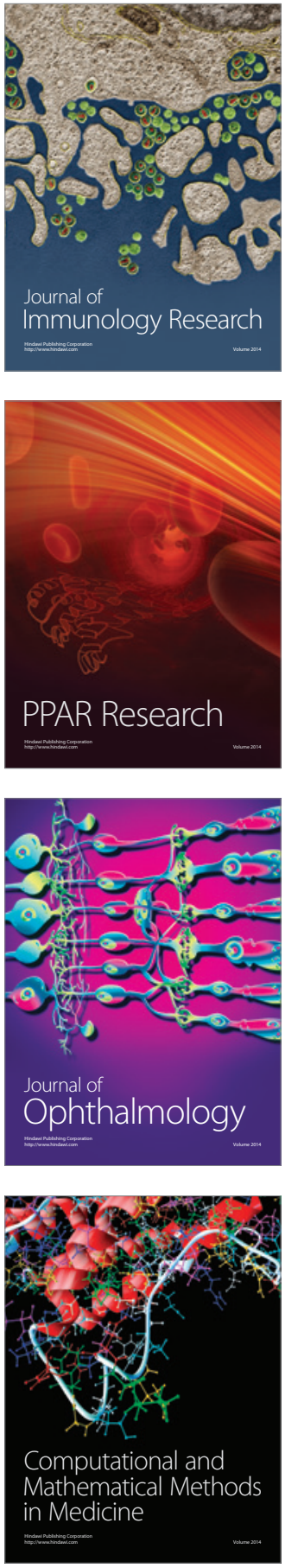

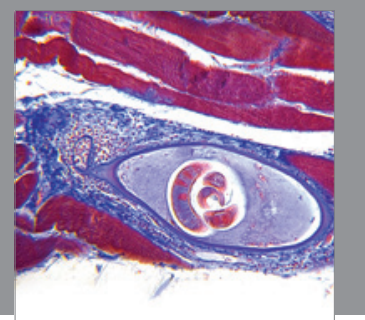

Gastroenterology

Research and Practice
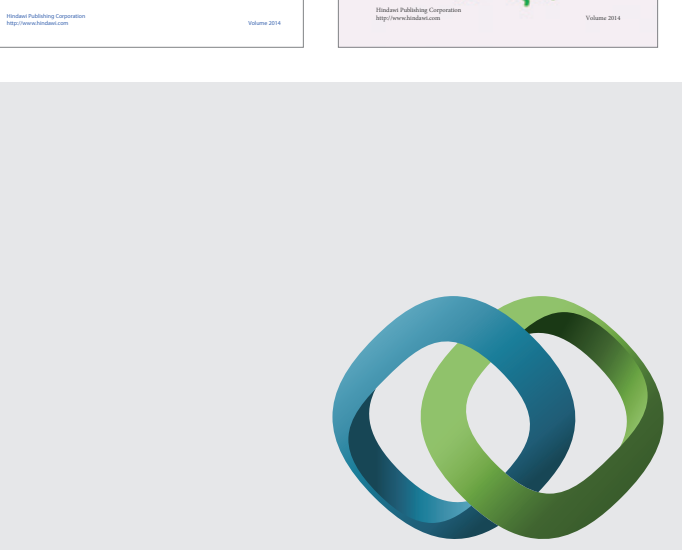

\section{Hindawi}

Submit your manuscripts at

http://www.hindawi.com
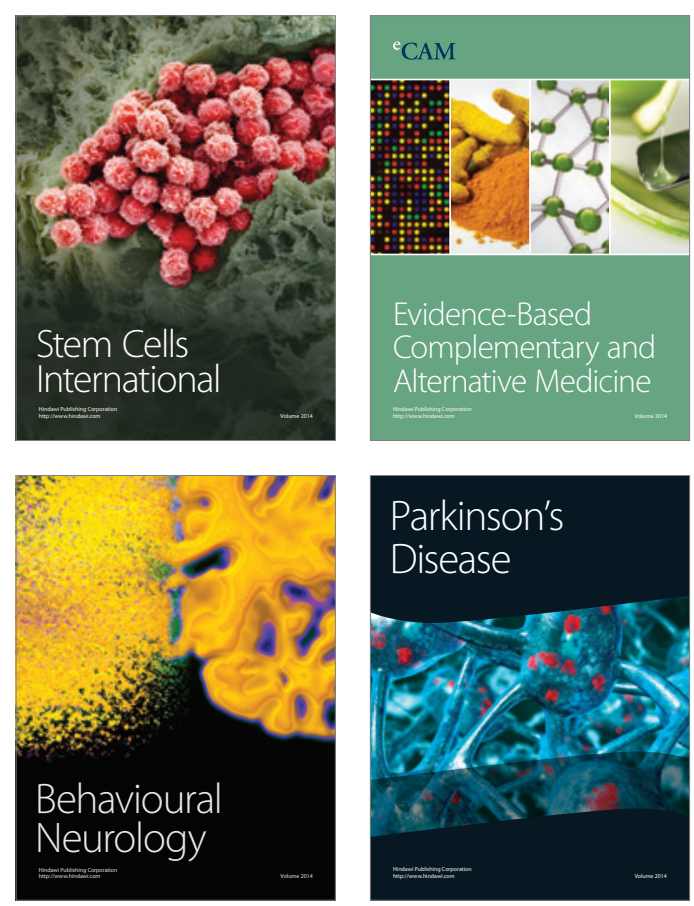

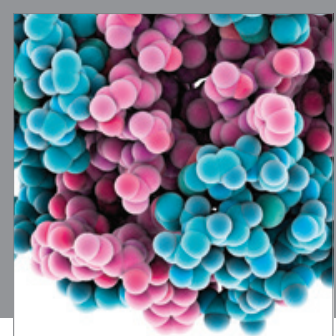

Journal of
Diabetes Research

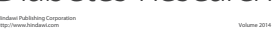

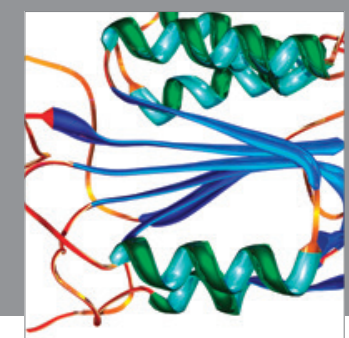

Disease Markers
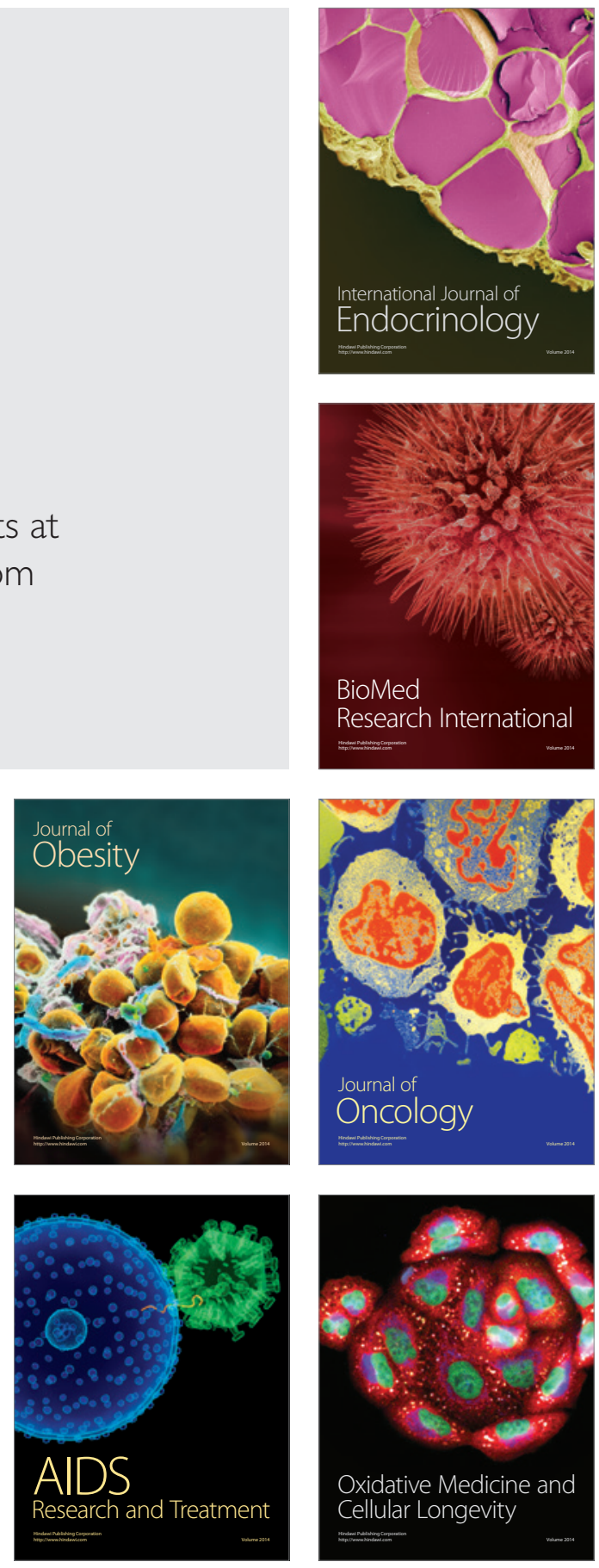